\title{
An Analysis of Blockchain Adoption in Supply Chains Between 2010 and 2020
}

\author{
Nikhil Vadgama* and Paolo Tasca \\ Centre for Blockchain Technologies, University College London, London, United Kingdom
}

In this research, the evolution of blockchain applied to supply chains has been mapped from the inception of the technology until June 2020, utilizing primarily public data sources. We have analyzed 271 blockchain projects on parameters such as their inception dates, types of blockchain, status, sectors applied to and type of organization that founded the project. We confirm generally understood trends in the blockchain market with new projects following the industry's general hype and funding levels. We observe most activity in the Agriculture/Grocery sector and the Freight/Logistics sector. We see the shift of market interest from private companies (startups) to public companies and consortia and the change in blockchain adoption from Ethereum to Hyperledger. Finally, we observe more market-ready solutions and fewer inactive projects for Hyperledger-based projects than Ethereum-based projects.

\section{OPEN ACCESS}

Edited by:

René Hüsler,

Lucerne University of Applied Sciences and Arts, Switzerland

Reviewed by:

Henry Michael Kim, York University, Toronto, Canada

Remo Pareschi,

University of Molise, Italy

*Correspondence:

Nikhil Vadgama nikhil.vadgama@ucl.ac.uk

Specialty section: This article was submitted to Non-Financial Blockchain, a section of the journal Frontiers in Blockchain

Received: 25 September 2020 Accepted: 29 January 2021

Published: 23 March 2021

Citation:

Vadgama $N$ and Tasca $P$ (2021) An Analysis of Blockchain Adoption in Supply Chains Between 2010 and 2020.

Front. Blockchain 4:610476. doi: 10.3389/fbloc.2021.610476
Keywords: blockchain, distributed ledger technologies, ethereum, hyperledger, supply chain, agriculture, freight, logistics

\section{INTRODUCTION}

Distributed Ledger Technology (DLT) promises to disrupt business models, business processes, and aspects of society by creating information systems that are transparent and provide a single point of truth for all members of a network (Pilkington, 2016). As an electronic ledger with the properties of decentralization, immutability, cryptography and smart contracts, DLT represents an innovation beyond traditional database technology (Iansiti and Lakhani, 2018).

Since the creation of DLT with Bitcoin in 2008 (Nakamoto, 2008), DLT's impact has begun to move outside of just the financial services domain into other sectors, including that of supply chains (Bünger, 2017; Hughes et al., 2019). Within the supply chain domain, it is widely acknowledged by many industry experts that DLT will have a tremendous impact on it, particularly around bringing transparency across various parts of it (Casey and Wong, 2017; O’Marah, 2017).

Supply chains underpin the smooth and timely movement of goods from producer through to consumer, and with increasing globalization, this coordination of goods underpins the globalized economy. The supply chain management sector stands at a size of $\$ 16$ trillion and has large overhead regarding fraud, errors and administration costs (Boucher, 2017).

Given the importance of this part of the world economy, it is astonishing that there is still a large degree of manual procedures and processes in operationally complex undertakings. For example, the shipment of refrigerated goods between East Africa and Europe can incorporate as many as 30 different individuals and organizations and involve over 200 different interactions and communications. The cost of processing all the paperwork associated with a shipment can easily be around $15 \%$ of the shipment costs (Groenfeldt, 2017). 
In light of recent events with the Covid-19 pandemic, the fragility of our current supply chains and globalized trade operations were exposed (Lin and Lanng, 2020). In particular, bringing supply chain infrastructure up to speed through digitization is important, and emerging technologies will play a part as the enabling force for economic, business and social transformation (Morkunas et al., 2019).

The relevance of blockchain for supply chains has already been widely discussed in academic literature (Kshetri, 2018). Much of the literature focuses on Bitcoin and explores potential applications. It does not describe the state of the market and its evolution (Min, 2019). Some studies exist that focus on survey-based methods including Petersen et al. (2018) who survey supply chain professionals on the use of blockchain and Fosso Wamba et al. (2020) who survey practitioners to investigate the drivers of blockchain adoption in the supply chain. ${ }^{1}$

This study offers a different perspective by exploring the state of blockchain adoption in supply chains based on publicly available data. As part of this research, 271 relevant blockchain projects were analyzed in the supply chain domain. Analysis of the data gathered through this research supports the narrative of both the general trends observed in the blockchain supply chain domain and concerning project inception dates, types of blockchain utilized, stages projects reached, sectors applied to and type of organization that founded the project. We confirm generally understood trends in the blockchain market with the creation of projects following the general hype and cryptocurrency market prices and funding levels in the market. We observe most activity occurring in the Agriculture/Grocery sector and the Freight/Logistics sector. We see the shift in market interest from primarily private companies (startups) to public companies and consortia, the change in blockchain adoption from Ethereum to Hyperledger and the status of projects that adopt these blockchains.

\section{MATERIALS AND METHODS}

Information on 271 projects utilizing blockchain for supply chain purposes was collected and analyzed between May and June 2020. Information was found from various sources through desktop research primarily of company websites, news articles, and data repositories (e.g. CBInsights ${ }^{2}$, Blockdata ${ }^{3}$ ). Information on projects was found was between 2010 and the first half of 2020. Raw data for 31 different fields was collected. An explanation of some of the more relevant fields for data collection is presented below, and in Appendix $\mathbf{1}$ and a full example of the cleaned data collected is presented for one particular project in Appendix 2.

${ }^{1}$ In this article we use the term "blockchain" to refer also to the larger family of DLT, i.e., community consensus-based distributed ledgers where the storage of data is not based on chains of blocks.

${ }^{2}$ https://www.cbinsights.com

${ }^{3}$ https://blockdata.tech
The methodological approach taken was first to collect raw data from multiple sources and then to clean it. After that, descriptive statistics were utilized to generate information on overall trends in the data. Finally, inferential statistics were applied to generate insights. Analysis was performed on the parameters of time, status, blockchain, sector, application area and organization type.

There were numerous difficulties in the collection of the dataset. This included the variety of sources that were required to gather information, as often data from one source would point to another with each presenting some new information that would be relevant for a particular project. There are also issues on the veracity of the data and whether the information found was completely verifiable. Where possible, every effort was taken to verify claims made by projects and companies through manual cross-validation. This aspect is discussed further below and in the challenges and the limitations section of this research. With regards to the main fields of analysis and data collected, this is further elucidated below.

Project organization classification: Projects were classified based on the type of organization leading a particular project. Rather than define a project by an organization, the term project is used as a single organization could have many different projects, and each project was classified separately. The four types of organizations that were used to classify projects were:

- Private companies-labelled as startups as the vast majority were early stage companies.

- Public companies-were those that are listed on public equity markets.

- Consortia-were identified by having either a separate legal entity or website and a degree of separation from the individual organizations taking part in the project (i.e. not being an organization and its clients).

- Government project-if a government body led a project.

Project status: several different classifications were used to describe the status of a project with respect to its progress, including:

- Inactive-explicit confirmation was found that the project was abandoned, social network accounts were no longer active, and the website had been taken down or had no update for longer than one year.

- In-development-the project is in the ideation stage or is completing a proof-of-concept or trial.

- Market-ready-the project is available for use in the market. This means that an organization is using it internally, or that partners and clients are using it or that the solution is available for use and is being sold by a vendor.

It should be noted here that the stages of inactive and marketready should not necessarily imply failure and success. There may be many reasons why a project is inactive, and some do not necessarily denote failure. Similarly, a project may appear to be market-ready without having any customers or having gone through a successful proof-of-concept. 
Supply chain application areas: where within the supply chain the project focused including:

- Product tracking/tracing - where information on the product could be traced through the supply chain relating to track and trace and product provenance.

- Logistics - the blockchain is utilized to capture information on the physical movement of the goods relating to automation, supply chain management and inventory management, use of IoT and cold chain and environment history recording.

- Financial transactions - where the project utilized the blockchain for payments in particular with the use of smart contracts, tokens and supplier reconciliation.

- Retail operations - where the blockchain is utilized for engagement with the end consumer with respect to loyalty management, refunds and customer identification.

- Circular economy - a project utilizes blockchain for the secondary use of goods and reselling, related to reduce, reuse, and recycle.

This particular taxonomy of application areas has been adapted from UCL Center for Blockchain Technologies. (2019). A project may belong to multiple application areas.

Sectors: Sectors considered for classification of the data were first based on the SIC classification system. This was too broad, so a sector classification based on the projects' natural and obvious sectoral classification was adopted. Sectors were classified if at least $1 \%$ of the data was present; otherwise, these projects were placed in the category Other. A Multiple classification was used for projects that were not sectorspecific. Clearly, identifiable sectors in the data that emerged were:

- Aerospace and Defense
- Agriculture/Grocery
- Automotive
- Fashion
- Finance
- Freight/Logistics
- Luxury items
- Mining
- Oil and Gas
- Pharma/Healthcare
- Multiple
- Other

Blockchains: The major blockchains classified include those that were identifiable in at least $1 \%$ of the data; otherwise, they were classified as Other. In many projects, the blockchain was not disclosed, and these projects had their blockchain categorized as $T B C$. Where a blockchain was utilizing an existing codebase and was not completely distinct from it, the blockchain from which the codebase derived was used to classify the project. The group Agnostic comprises solutions that were not tied to any particular blockchain. The blockchain classifications used were:
- Ant Blockchain
- Bitcoin
- Corda
- Ethereum
- Hyperledger
- Oracle Blockchain
- Quorum
- VeChain
- Agnostic
- Other
- $T B C$

\section{RESULTS}

We present the results on 271 blockchain projects based on the year in which the project was created, the blockchains used, the stage the project has reached, the supply chain application area, the organization leading the project and the sector the project was applied in.

Figure 1 shows the number of projects with respect to their founding year. The peak of projects being created is in 2018, with $57 \%{ }^{4}$ of all projects founded in 2017 and 2018 alone. After 2018 we see the number of projects fall. 2020's data is only partial for the year (until June), but already has nearly as many projects as 2015. No projects were discovered that were founded in 2011.

Figure 2 shows the percentage of projects that use different blockchains based on their founding years. The major blockchains adopted are Ethereum, utilized by $23 \%$ of all projects and Hyperledger, utilized by $21 \%$ of all projects. $13 \%$ of projects are blockchain agnostic. ${ }^{5} 23 \%$ of projects do not disclose the blockchain that they use and are in the TBC category. These projects are still experimenting or deciding which blockchains to use (and in some cases, these projects no longer exist) ${ }^{6}$, or they are operating and do not wish to disclose what type of blockchain solution they utilise. ${ }^{7}$ We also see that projects developed on the Ethereum platform were more prevalent than Hyperledger projects in 2015, 2016, and 2017, whilst this is opposite for projects created in 2018, 2019 and for 2020 so far. The greatest proportion of Ethereum projects were from projects created in 2017, with $40 \%$ of all Ethereum based projects created in this year. This is approximately two years after the release of Ethereum in July 2015 (Etheruem, 2020), indicating a lag in the creation of projects using this blockchain (as it appears today).

On the other hand, the greatest proportion of Hyperledger projects was in 2018 with $38 \%$ of all projects utilizing Hyperledger. Again this also follows a lag of approximately two years after the creation of Hyperledger in late 2015, early 2016 (Hyperledger, 2020). Projects in the Agnostic group accounted for the largest percentage of projects founded in

\footnotetext{
${ }^{4}$ Throughout this research any statistics that utilize percentages are rounded to the nearest whole number.

${ }^{5}$ An example project in this category would be Origintrail (https://origintrail.io), who have a protocol that can work with different blockchain solutions.

${ }^{6}$ See for example Resonance (https://www.digicatapult.org.uk/for-startups/successstories/resonance)

${ }^{7}$ See for example Remedichain https://www.remedichain.org
} 


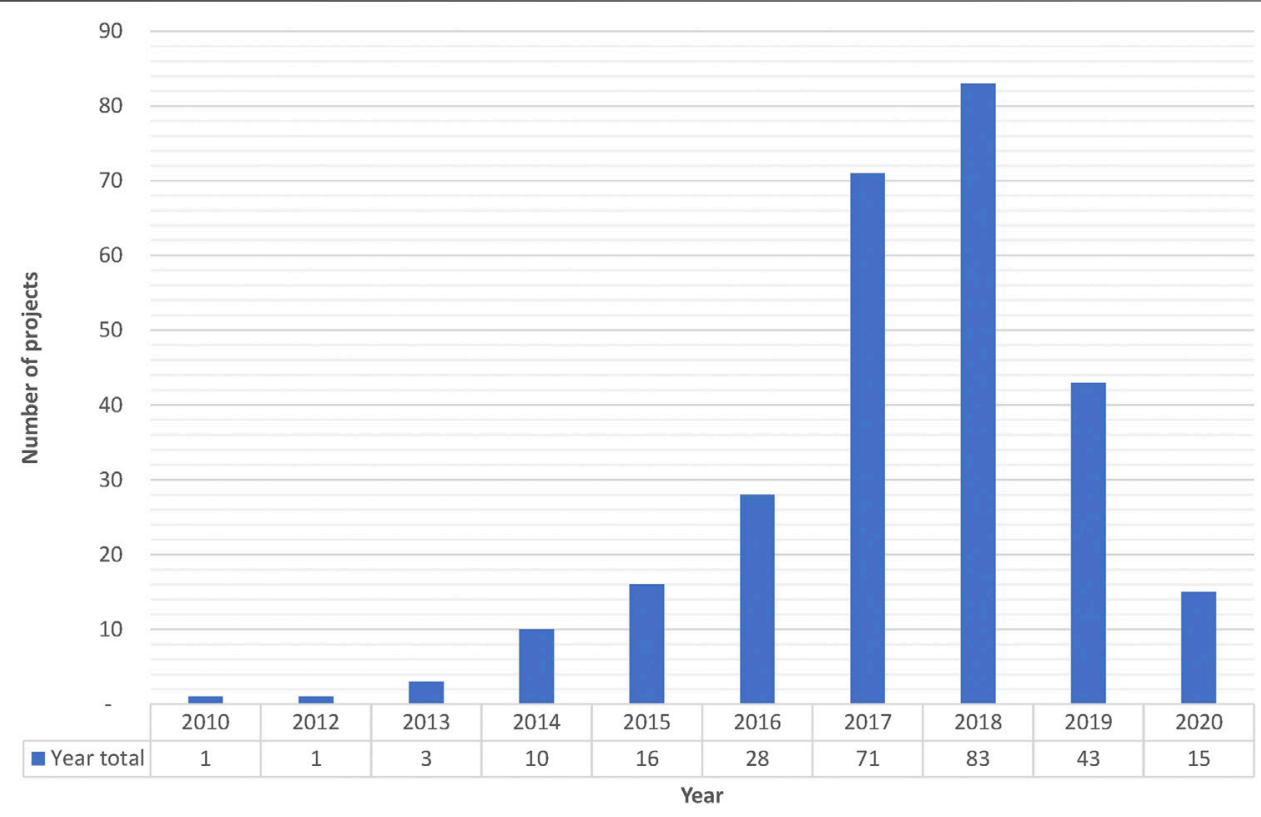

FIGURE 1 | The number of blockchain projects created in each year.

2014 , but fluctuate under $20 \%$ over other years. Finally, projects in the TBC group are approximately $25-30 \%$ of all projects in each of 2016, 2017 and 2018.

Figure 3 shows the status of projects based on the year they were created. Out of the entire dataset, $23 \%$ of projects can be classified as market-ready, $67 \%$ can be said to be in-development, and $10 \%$ identified as inactive. The greatest proportion of projects that can be classified as market-ready are from 2014, 2015, and 2017 with 50\%, $38 \%$ and $31 \%$ of projects respectively. 2016 appears to be an anomaly with only $14 \%$ of projects from that year appearing to be marketready. The greatest proportion of projects that appear to be marketready occurred in 2017; 35\% of all market-ready projects were created in that year. Many projects also appear stuck in the indevelopment stage, and a minority of projects appear to be inactive. 2017 and 2018 feature the greatest proportion of inactive projects, with $35 \%$ and $46 \%$ of all inactive projects (81\%) occurring from projects created in these years.

Figure 4 shows the lead organization of a project by the founding year of the project. Startups account for $64 \%$ of the entire dataset, followed by public companies at $17 \%$, consortia at $15 \%$ and finally, government initiatives at $4 \%$. Startups account for all projects in 2014 and 2015 and then decline over time, accounting for only $26 \%$ of all projects created in 2019 . Other types of organizations enter into the fray from 2016 onwards. Of all startup projects, 35\% of them were created in 2017 alone.

After analyzing projects along various dimensions based on the year they were created, we now analyze all the projects irrespective of time.

Figure 5 shows the status of a project based on the applied blockchain solution. Of interest is that greatest proportion of projects that appear market-ready are Hyperledger based, with $33 \%$ of projects with this status. Also of interest is that of those projects identified as being inactive, $35 \%$ of these are utilizing the Ethereum platform. Other interesting points to note are that many projects that appear to be marketready have not revealed what blockchain technologies that they are working with, which is for example why $16 \%$ of projects with market-ready status are in the TBC category. Of all the projects that utilize Hyperledger, $47 \%$ of them are indevelopment, $36 \%$ of them are market-ready and only $2 \%$ appear inactive. Compared to all Ethereum projects, $50 \%$ appear to be in-development, $21 \%$ appear to be marketready, and $15 \%$ appear to be inactive.

Figure 6 shows the supply chain application areas that projects are working on. The majority of projects are involved in the classification of product tracing/tracking, with nearly $66 \%$ of projects focused here. Second is the logistics classification, with $44 \%$ of projects using automation, IoT, and sensors in the supply chain to track products' movements and status. Financial transactions are also significant, with $24 \%$ of projects identified with this use case. Finally, the two smallest application areas are circular economy with $8 \%$ and retail operations, with $7 \%$ of all projects. In particular, the recent interest in the circular economy area, relevant to sustainability, shows growth from previous work on identifying projects by UCL Center for Blockchain Technologies (2019). Also, retail operations, where the blockchain meets the consumer, may be considered a more high-risk development area and may explain the lower amount of progress in this area.

Figure 7 shows the blockchains used by projects based on the type of lead organization. Ethereum dominates the startup category, with $32 \%$ of all startup projects utilizing this platform. For consortia and public companies, Hyperledger is the most popular used $35 \%$ and $34 \%$ respectively. For government initiatives, $50 \%$ of projects did not identify the blockchains they utilized (TBC). Out of all Ethereum projects, 


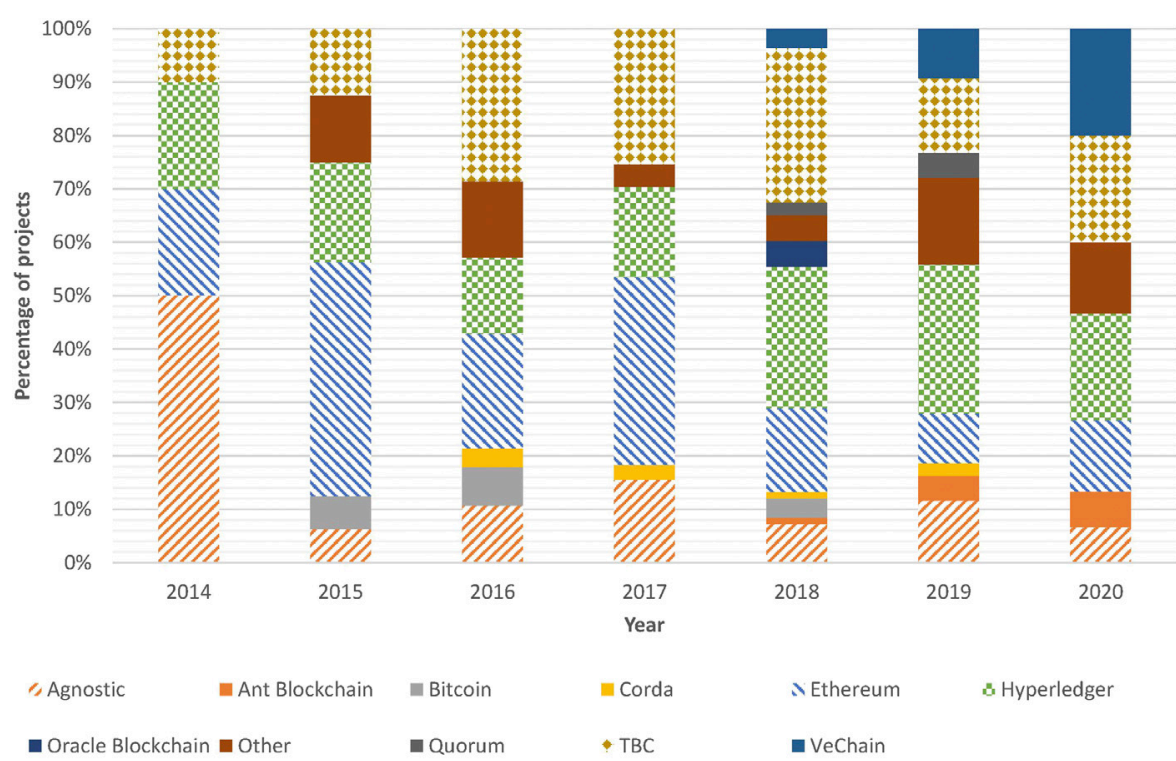

FIGURE 2 | The percentage of projects using a particular blockchain based on the project's year of creation.

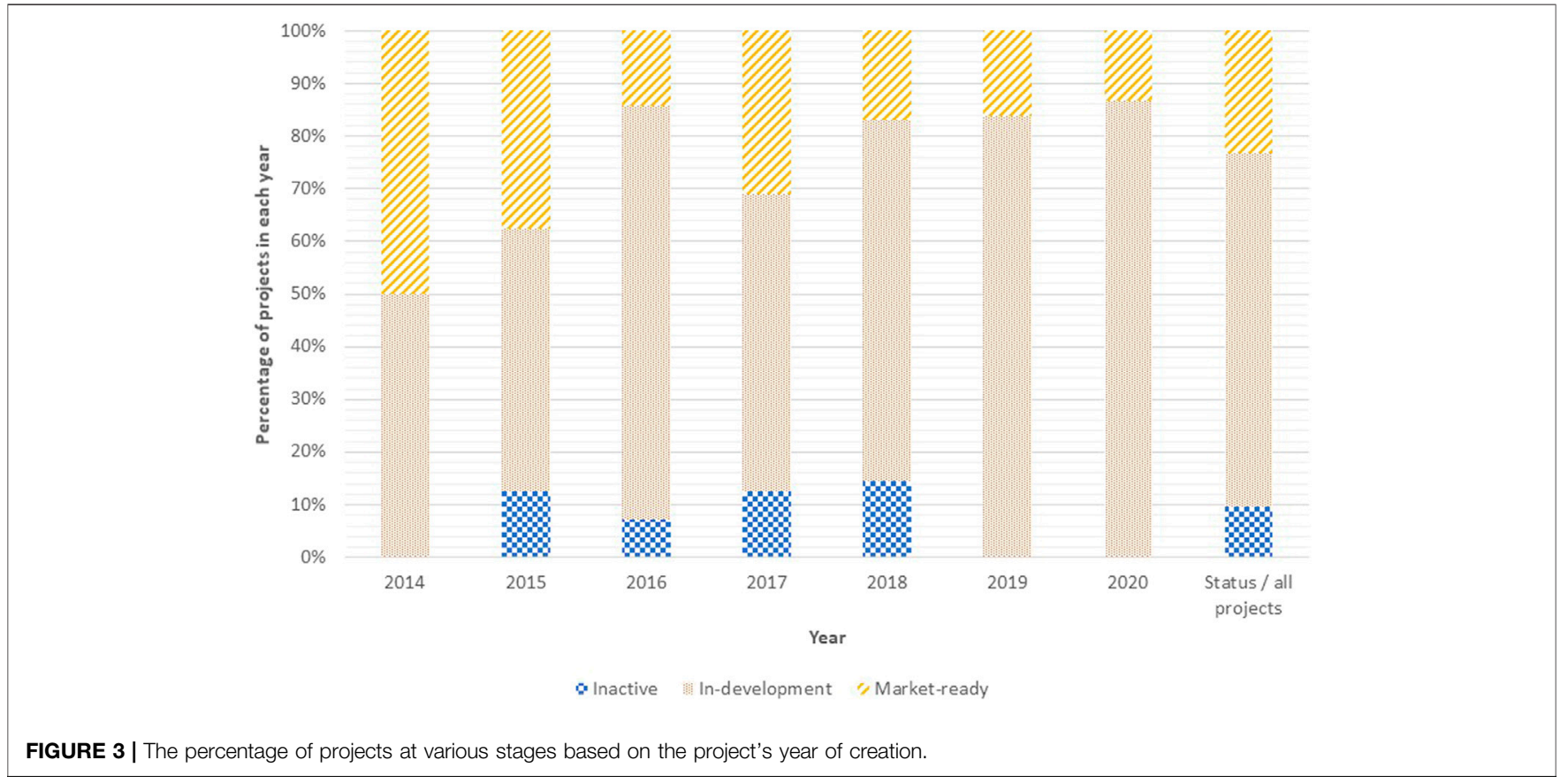

$90 \%$ were utilized by startups. Of all Hyperledger projects, consortia, public companies and startups utilized this blockchain at $24 \%, 28 \%$ and $45 \%$. Overall, startups utilizing Ethereum accounted for $21 \%$ of the dataset as the largest single group.

Figure 8 shows the projects that operate in different sectors based on the type of organization leading the project. Within the dataset, the largest sectors that projects were applied to were the Agriculture/Grocery, Freight/Logistics, Multiple and Finance sectors with $40 \%, 17 \%, 13 \%$ and $9 \%$ of all projects respectively. Agriculture/
Grocery projects account for the greatest share in each of the different organization types with $25 \%, 60 \%, 32 \%$ and $44 \%$ of consortia, government initiatives, public companies, and startups. Freight/Logistics is the second-largest sector that projects operate in with $23 \%, 20 \%, 4 \%$ and $19 \%$ of projects in each of the consortia, government initiative, public company and startup categories. Startups are also engaged in the most number of sectors, followed by consortia and public companies. Government initiatives operate in the least number of sectors. 


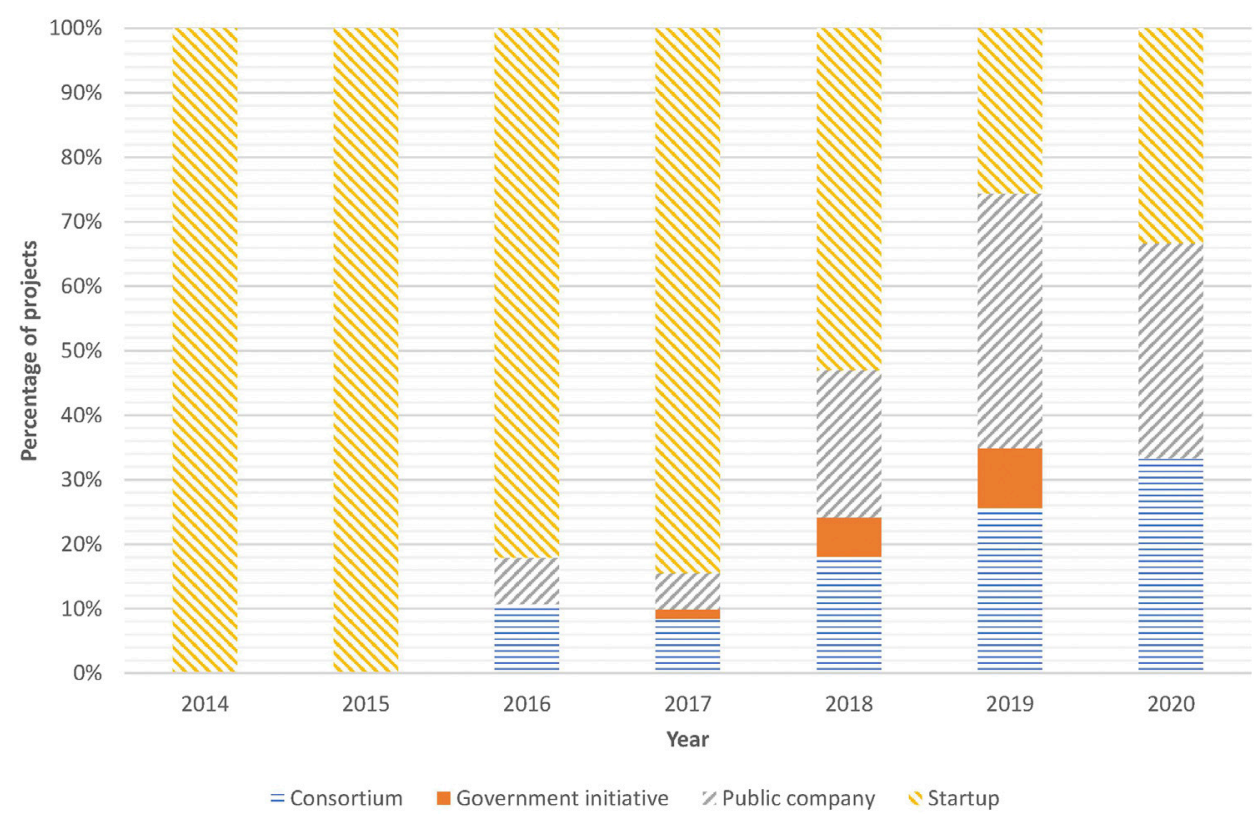

FIGURE 4 | The percentage of different types of organization leading projects based on the project's year of creation.

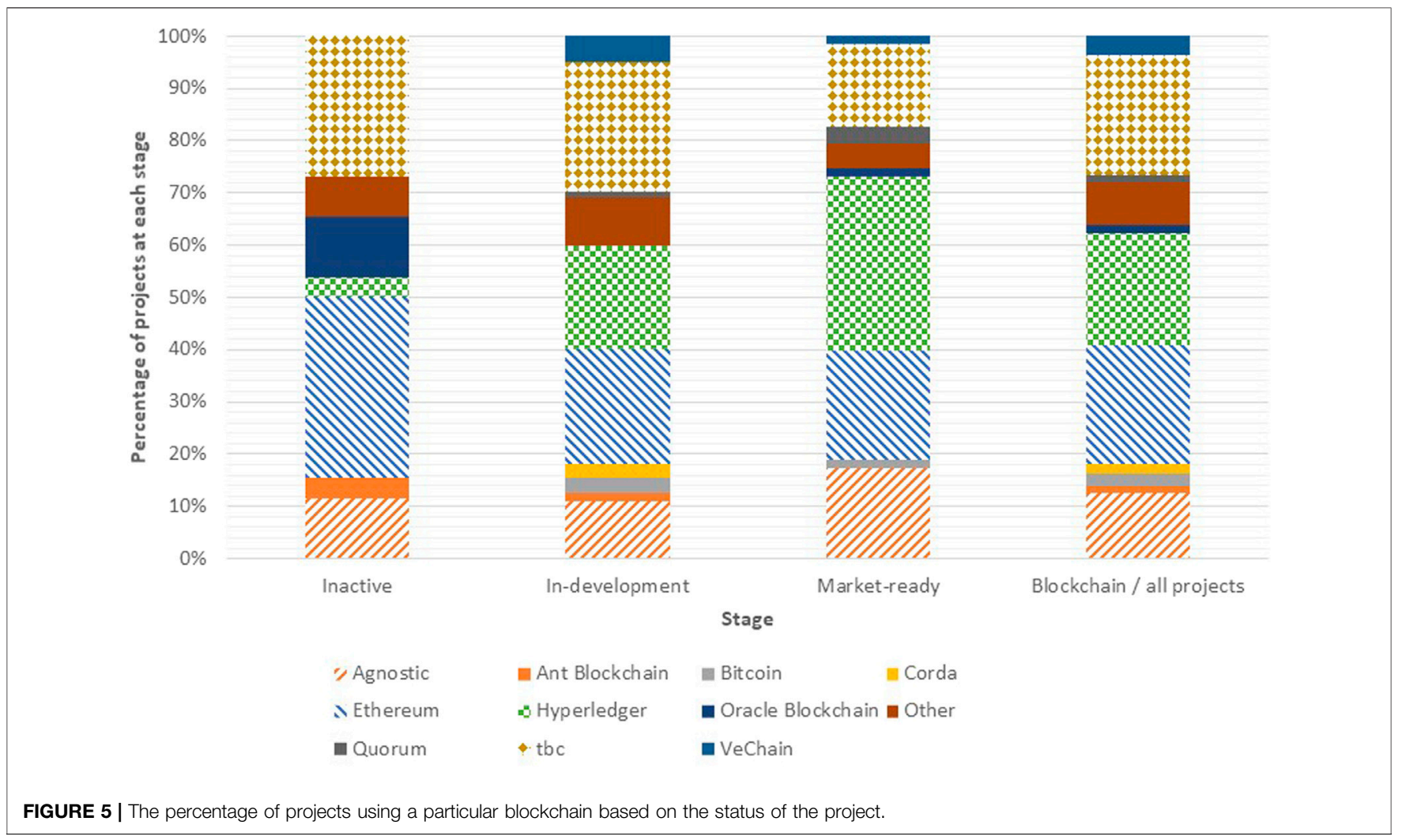

In this last part of the analysis, we look more closely at projects that are utilizing the Hyperledger and Ethereum blockchains and also at projects operating in the Agriculture/Grocery and Freight/
Logistics sectors. We look at these subsets as these two sectors, and blockchains account for $57 \%$ and $44 \%$ of all projects respectively. 


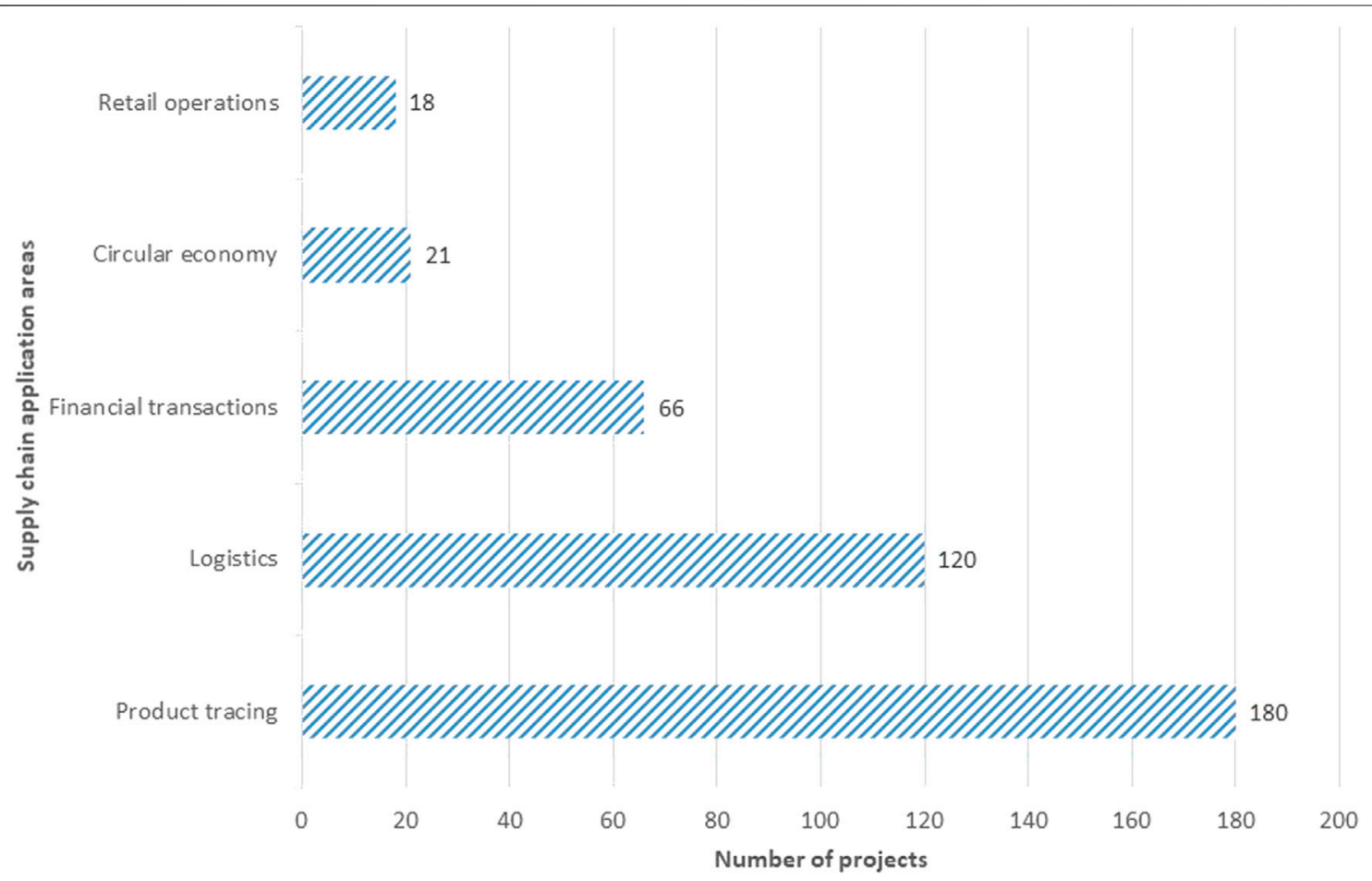

FIGURE 6 | The number of projects focused on a particular supply chain application area.

Focusing on Ethereum based projects only, Table 1 shows the status of projects broken down into their leading organizations. Here we see that the vast majority of Ethereum projects are led by startups (90\%) compared with all of the projects in our entire dataset (64\%). Concerning the status of a project, the proportion of inactive Ethereum projects $(15 \%)$ is greater than the entire dataset $(10 \%)$. Finally of all Ethereum projects, $21 \%$ appear to be market-ready compared with $23 \%$ from the entire dataset.

We repeat the same analysis as above for Hyperledger-based projects only. Table 2 shows the status of Hyperledger projects broken down into their leading organizations. Of all the Hyperledger projects, $83 \%$ are based on Hyperledger Fabric. 9\% utilized Hyperledger Sawtooth, and 2\% utilized Hyperledger Besu and Grid each. It was not possible to determine which variant of Hyperledger 5\% of projects utilized. Differently from Ethereum projects, we see that fewer Hyperledger projects are led by startups (45\%). We also observe that Hyperledger projects are led by consortia and public companies $24 \%$ and $28 \%$, respectively. This is higher than the dataset average, where we find that consortia and public companies lead $15 \%$ and $17 \%$ of all projects respectively. Moreover, we find that of all Hyperledger projects, 36\% appear to have a market-ready status. This percentage is higher than the projects that appear market-ready in the entire dataset $(23 \%)$. Hyperledger projects' inactivity rate is also very low (1\%) compared with the entire dataset (10\%).

Table 3 compares Hyperledger and Ethereum projects in the Agriculture/Grocery and Freight/Logistics sectors. Here we see that Hyperledger has a greater percentage of projects that appear to be market-ready and fewer inactive projects than Ethereum in the Agriculture/Grocery sector. For the Freight/Logistics sector, Ethereum has more market-ready and inactive projects than Hyperledger. To summarize, Hyperledger based projects appear to be less inactive and appear to be more market-ready compared with Ethereum based projects and compared to the entire dataset.

Table 4 shows the percentage of projects using either Hyperledger or Ethereum in a particular year and within a particular sector compared to the averages for all sectors. Here we can see that for the Agriculture/Grocery sector, Ethereum usage is higher for projects created in 2014, 2015, and 2016 than Ethereum-based projects in all sectors and for Hyperledger projects. For 2017-2020, the proportion of Ethereum projects is lower than Ethereum projects in all sectors. For 2018-2020, the proportion of Hyperledger projects are greater than Ethereum in the Agriculture/Grocery sector. For the Freight/Logistics sector, the proportion of Ethereum projects tend to be greater than Hyperledger (except in 2014 where they are equal and 2018 where there are more Hyperledger projects).

\section{DISCUSSION}

Based on the results, several general findings emerge that showcase how blockchain projects are evolving in the supply chain arena. Many of the findings fit industry reporting, news, and survey results available in the public domain (for example, 


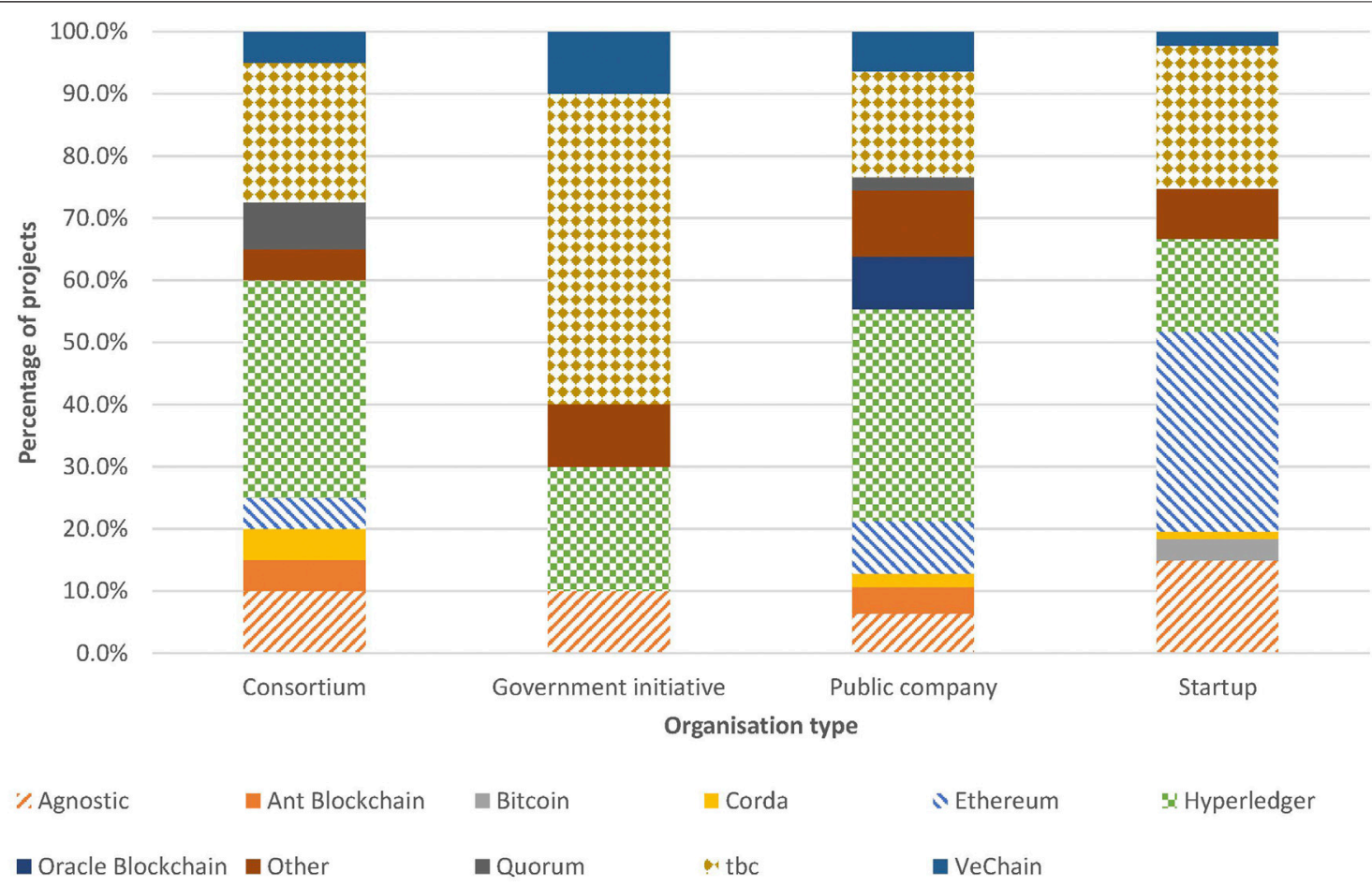

FIGURE 7 | The percentage of projects using a particular blockchain based on the type of organization leading the project.

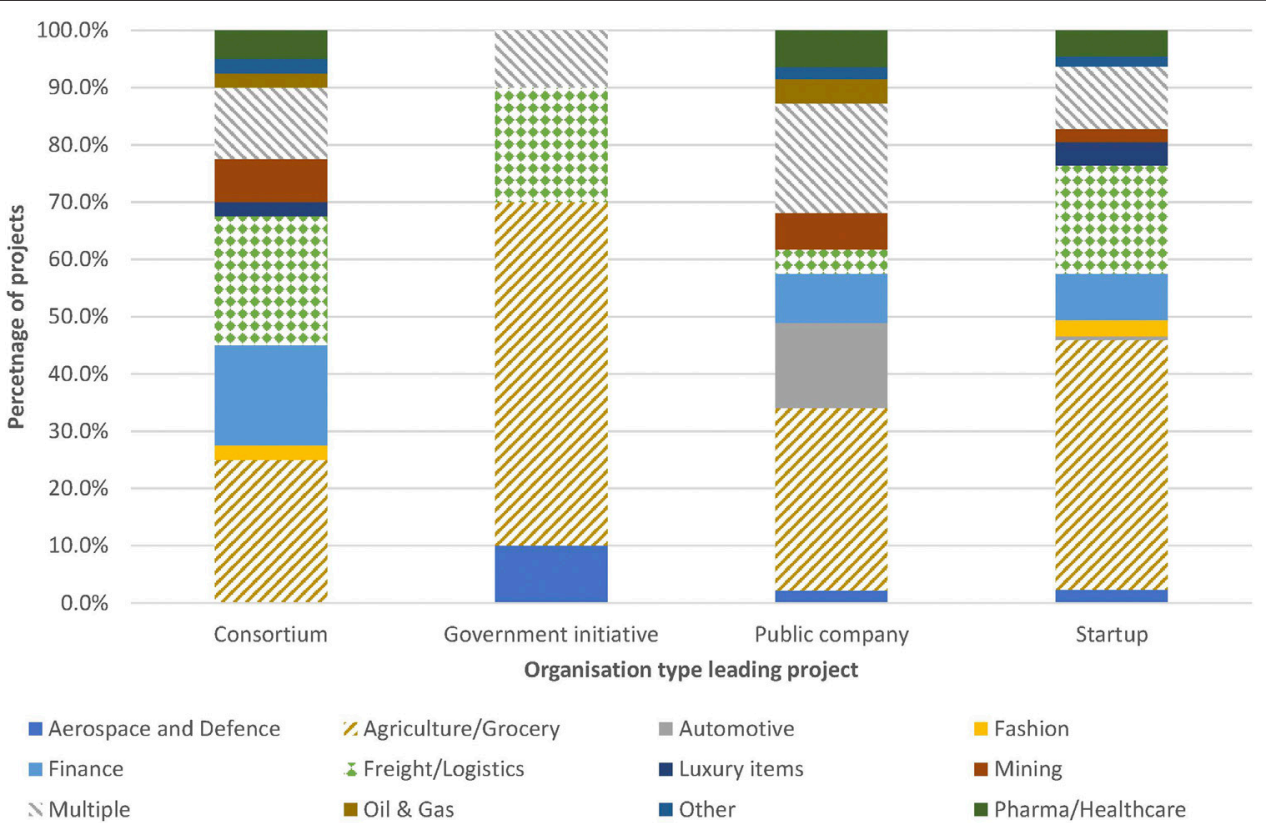

FIGURE 8 | The percentage of projects operating in different sectors based on the type of organization leading the project.

see Deloitte, 2020). In line with general interest indicators such as google trends (search term "blockchain") (Google, 2020) and cryptocurrency prices (Bitcoin's peak price in late 2017) (CoinMarketCap, 2020), we see these patterns of peak interest and price match the pattern of new projects being created. New project formation peaks in 2018 and then drops off in 2019 and 2020. This is most clearly seen in Figure 1, showcasing the number of projects by their creation year. 
TABLE 1 | Ethereum based projects and the stages that they have reached based on the leading organization of the project. ${ }^{a}$

\begin{tabular}{|c|c|c|c|c|c|}
\hline \multirow[t]{2}{*}{ Organization type } & \multicolumn{4}{|c|}{ Stage ( $\%$ of all ethereum based projects) } & \multirow{2}{*}{$\begin{array}{l}\text { Organization total (for } \\
\text { all projects) (\%) }\end{array}$} \\
\hline & Inactive & In-development & Market-ready & Organization total & \\
\hline Consortium & 0 & 3 & 0 & 3 & 15 \\
\hline Government initiative & 0 & 0 & 0 & 0 & 4 \\
\hline Public company & 0 & 6 & 0 & 7 & 17 \\
\hline Startup & 15 & 55 & 21 & 90 & 64 \\
\hline Stage total (\% of all ethereum based projects) & 15 & 65 & 21 & & \\
\hline Stage total (\% of all projects) & 10 & 67 & 23 & & \\
\hline
\end{tabular}

${ }^{a}$ Numbers may not sum due to rounding.

TABLE 2 | Hyperledger based projects and the stages that they have reached based on the leading organization of the project. ${ }^{2}$

Organization type

Stage (\% of all hyperledger based projects)

Inactive In-development Market-ready Organization total (\%)

Organizational total (for all projects) (\%)

\begin{tabular}{lc}
\hline Consortium & 2 \\
Government initiative & 0 \\
Public company & 0 \\
Startup & 0 \\
Stage total (\% of all hyperledger based projects) & 2 \\
Stage total (\% of all projects) & 10
\end{tabular}

${ }^{a}$ Numbers may not sum due to rounding.

TABLE 3 | Comparison of projects that use Hyperledger and Ethereum within the Agriculture/Grocery and Freight/Logistics sectors. ${ }^{2}$

\begin{tabular}{|c|c|c|c|c|}
\hline Blockchain & Sector/Stage & Inactive (\%) & In-development (\%) & Market-ready (\%) \\
\hline \multirow[t]{3}{*}{ Ethereum (\% of all ethereum projects in that sector and stage) } & Agriculture/Grocery & 12 & 72 & 16 \\
\hline & Freight/Logistics & 15 & 38 & 46 \\
\hline & Stage total & 15 & 65 & 21 \\
\hline \multirow[t]{3}{*}{ Hyperledger (\% of all hyperledger projects in that sector and stage) } & Agriculture/Grocery & 0 & 65 & 35 \\
\hline & Freight/Logistics & 0 & 80 & 20 \\
\hline & Stage total & 2 & 62 & 36 \\
\hline Percentage of all projects at each stage & & 10 & 67 & 23 \\
\hline
\end{tabular}

${ }^{a}$ Numbers may not sum due to rounding.

As well as the number of projects being created each year, we see the market shift from being a startup, and private company dominated one to enterprise and consortium dominated. With regards to startups and private companies, as shown in Figure 4, we see the percentage of private company projects changing from $100 \%$ in 2014 to $26 \%$ in 2019 and 33\% for the first half of 2020 . This shows that more public companies are coming to the fray to engage in projects, as well as consortia and government initiatives. Public companies account for the majority at $40 \%$ of all projects in 2019.

Further confirming the movement from private companies to public company led projects is the change in the blockchain platforms utilized. Of identifiable blockchains, Ethereum represents $23 \%$ of projects in the sample, and Hyperledger represents $21 \%$ of projects. We see that Ethereum projects account for $44 \%, 21 \%$ and $35 \%$ of projects created in 2015, 2016, 2017, and then Hyperledger dominating in 2018,2019 and 2020 with $27 \%, 28 \%$ and $20 \%$ respectively as seen in Figure 2. Part of this switch is due to the differences in the creation dates of the blockchains. Ethereum was launched in 2015 (Etheruem, 2020), whilst Hyperledger in 2016 (Hyperledger, 2020). The use of these blockchains can be seen in Figure 7. As public companies become dominant in 2018 and 2019 , we see that $34 \%$ of all public company projects utilize Hyperledger (the majority being Hyperledger Fabric-based), whilst 32\% of all startup projects utilize Ethereum.

One interesting point to examine is the number of projects that do not identify the blockchain that they use. As shown in Figure 2, overall, 23\% of all the projects are in the $T B C$ category. This may be because the projects are still in-development and they wish to keep this information proprietary. $73 \%$ of the projects in the $T B C$ category have an in-development status, more than for Ethereum or Hyperledger (65\% and $62 \%$ of those projects). TBC projects account for the largest percentage of all projects with an in-development status with 34\%, which represents the largest grouping and suggests that these projects are still experimenting. 
TABLE 4 | Comparison of Ethereum and Hyperledger projects in the Agriculture/Grocery and Freight/Logistics sectors over timea

\begin{tabular}{|c|c|c|c|c|c|c|c|c|}
\hline Sector & Blockchain/Year & $\begin{array}{c}2014 \\
(\%)\end{array}$ & $\begin{array}{c}2015 \\
(\%)\end{array}$ & $\begin{array}{c}2016 \\
(\%)\end{array}$ & $\begin{array}{c}2017 \\
(\%)\end{array}$ & $\begin{array}{c}2018 \\
(\%)\end{array}$ & $\begin{array}{c}2019 \\
(\%)\end{array}$ & $\begin{array}{r}2020 \\
(\%)\end{array}$ \\
\hline \multirow{2}{*}{$\begin{array}{l}\text { Agriculture/Grocery (\% of projects in the sector that use that particular } \\
\text { blockchain) }\end{array}$} & Ethereum & 50 & 71 & 22 & 28 & 15 & 6 & 0 \\
\hline & Hyperledger & 25 & 29 & 22 & 14 & 18 & 22 & 50 \\
\hline \multirow[t]{2}{*}{ Freight/Logistics (\% of projects in the sector that use that particular blockchain) } & Ethereum & 0 & 100 & 20 & 50 & 8 & 20 & 0 \\
\hline & Hyperledger & 0 & 0 & 10 & 7 & 23 & 0 & 0 \\
\hline \multirow[t]{2}{*}{ All sectors (blockchain used as a percentage of all projects from that year) } & Ethereum & 20 & 44 & 21 & 35 & 16 & 9 & 13 \\
\hline & Hyperledger & 20 & 19 & 14 & 17 & 27 & 28 & 20 \\
\hline
\end{tabular}

${ }^{a}$ Numbers may not sum due to rounding.

Concerning the status of a project, one would expect that projects that have existed for longer (and created earlier) would perhaps have had more time to experiment and become marketready. This is confirmed in Figure 3 where we see that projects created in 2014 and 2015 have a market-ready status at 50\% and $38 \%$, respectively. Concerning inactivity, 2018 has the highest proportion of projects that are inactive, with $15 \%$ of all projects created in that year being inactive. Due to the large number of projects created on the back of hype in the sector, these projects were less thought through and had lower chances of developing and becoming market-ready. In particular, the boom in Initial Coin Offerings (ICO) occurred with the peak in cryptocurrency prices and projects' formation, decreasing the barriers to starting a project as funding was more accessible. Funding peaked for ICO's in 2018 at $\$ 12.62$ billion (Liu, 2020), after the peak in Bitcoin's price in late 2017 (CoinMarketCap, 2020). The observed pattern of projects created very much fits the funding cycle for 2017, 2018 and 2019 (Tasca et al., 2018).

Another interesting fact to note is the relatively large number of projects with an in-development status. $67 \%$ of all projects are classified as in-development, with $28 \%$ of all projects with this status created in the years between 2014 and 2017. There may be two reasons for this. The first could be that projects are particularly complex and take many years to develop. This is certainly described in the literature (see, e.g. Iansiti and Lakhani, 2018) which states that it will take years for blockchain as a foundational technology to change the supply chain landscape. The second reason could be that organizations wish to signal that projects are still active to either not admit failure, or to be ready to revive a project when the time in the market for deployment is right. For projects led by public companies, consortia, and government initiatives, a greater percentage than the dataset average $(67 \%)$ have an in-development status. However, it should also noted that these projects are not as old as startup ones.

With respect to project status and organizations, the greatest proportion (29\%) of startup projects have a market-ready status. Government projects have the most inactive projects, which stands at $20 \%$ of all government projects. This may be because government projects have a greater degree of complexity than private sector projects due to legislative issues and accompanying bureaucracy, explaining why fewer government initiatives have become available in the market.

With respect to sectors, Agriculture/Grocery dominates throughout all years and accounts for $40 \%$ of the dataset.
Food safety is of paramount importance, and so is the ability to track and trace agriculture and grocery products. This may explain why the majority of projects that utilize blockchain are concentrated in this sector. The need for this is brought particularly to light given scandals in recent years where there have been incidents of milk powder contamination (Xiu and Klein, 2010), E-coli outbreaks (Casey and Wong, 2017) and meat substitution (Falkheimer and Heide, 2015).

Freight/Logistics is the second-largest sector accounting for $17 \%$ of all projects. As discussed earlier, the complexity of moving products for example from East Africa to Europe required over 200 interactions and involved more than 30 individuals and organizations in the journey and had costs of paperwork exceeding $15 \%$ of the entire transportation cost (Bajpai, 2017 and; Groenfeldt, 2017). This complexity implies potentially large efficiency gains that could be made which explains the attention given to these sectors. Agriculture is also the dominant sector amongst organization types leading projects and is largest for government-led projects, with $60 \%$ of these projects taking place in the agriculture sector (above the $40 \%$ for all projects). Out of all consortia led projects, $23 \%$ are in the Freight/Logistics sector, greater than the dataset average (15\%). This may reflect the sector's relative coordination complexity, implying greater coordination of stakeholders needed, which consortia with their governance structures may facilitate.

When looking at the supply chain's application areas, we see that the greatest focus is in the product tracking/tracing area. This is to be expected given this is the most apparent use of blockchain to coordinate and track information. Second is the application area of logistics, which involves more complexity and IoT and sensors to track information related to the goods' physical movement. It should be noted that in many cases the areas of product tracing and the area of logistics overlap ( 65 projects), as we see $36 \%$ of all projects that focus on product tracing also engaging in logistics, and $54 \%$ of projects that engage in logistics also having product tracking. We observe that $39 \%$ of all projects operate with more than one application area. The area of financial transactions is also non-negligible with 66 projects that overlap the most with the logistics area (33 projects), more than any other-particularly here the use of sensors to automatically update information related to smart contracts facilitating contractual obligations will be important. This area should be expected to grow as tokenization of physical assets become more prevalent. 
Finally, it is interesting to see that the circular economy area is growing with its relative importance to sustainability. Retail operations have the least activity given the risks of dealing with end-consumers.

Of most interest is comparing Ethereum and Hyperledger projects, and comparing projects in the Agriculture/Grocery and the Freight/Logistics sectors.

The results show that Ethereum has a much greater proportion of startups (90\% of all projects) than the average across all projects (Table 1). This is very different from Hyperledger, which has a lower proportion of startups ( $45 \%$ of all projects), but a relatively higher proportion of consortia and public companies (Table 2). This distinction can be attributed to the different nature of the blockchains. Ethereum is a public blockchain and relatively easy to fundraize for with tokens, particularly during the ICO boom as seen in 2017. Hyperledger, on the other hand, is more suited for private usage and therefore fits use by enterprises, or public companies.

On the proportion of projects that appear inactive compared to market-ready, Ethereum shows a higher degree of inactivity and a lower level of market-readiness than the average rate of all the dataset projects. On the opposite side, Hyperledger projects show a lower inactivity rate than the average rate of all the projects in the dataset. Moreover, Hyperledger projects show a higher market-readiness. It is interesting to note why this may be the case, and perhaps this is to do with the nature of blockchain implementation. It is much easier to implement projects amongst an ecosystem if one is the dominant player. Public companies are much more likely to exhibit this behavior, and indeed, we see this in the case of Hyperledger with $24 \%$ of all market-ready projects coming from public companies and $31 \%$ of all public companies utilizing Hyperledger with this status. Indeed, given the origins of Hyperledger Fabric, the dominant Hyperledger variant seen within this research, created by IBM (Androulaki et al., 2018), public companies may have a greater inclination to trust this technology for use over others.

The above results may also find an explanation from Fosso Wamba et al. (2020) findings according to which knowledge sharing and trading partner pressure lead to successful outcomes for the adoption of blockchain in supply chains. This supports the assertion that public companies (due to their size and influence) are more likely to be able to create pressure on organizations in their ecosystem to adopt blockchain, thereby potentially leading to greater success for projects. Indeed, the very small number of public companies, consortia or government initiatives leading Ethereum based projects can explain the lower statistics for market-ready projects we see for this blockchain.

Finally, Table 4 shows the trends in Hyperledger and Ethereum adoption over time for all projects and the Agriculture/Grocery and Freight/Logistics sectors. As discussed earlier, the shift from Ethereum to Hyperleger can be seen occurring in 2018. This pattern is also seen in the Agriculture/ Grocery sector, but not in the Freight/Logistics sector. This may be explained by the fact that Freight/Logistics projects have greater complexity and involve cross border provenance, for instance, requiring the use of public blockchains over private ones, and hence the utilization of Ethereum here. Indeed, we can observe that Ethereum has more market-ready projects than Hyperledger in the Freight/Logistics sector $(46 \%$ of those projects compared to $20 \%$ ).

\section{CHALLENGES IN THE RESEARCH, LIMITATIONS AND FUTURE DIRECTIONS}

This research's limitations are primarily based on the difficulty of sourcing full information on the nature of blockchain projects in supply chains. Although there exist some repositories of project information, there are still many more projects that were found by searching online, looking at company websites and examining general press and news reports. It was also challenging to find good quality data on the nature of blockchains in supply chains. This limited the amount of analysis that could be completed. For example, it would be interesting to examine the funding levels for projects. However, within our sample, funding data was only available for $28 \%$ of projects and therefore deemed not large enough to draw meaningful conclusions. Furthermore, when completing desktop research examing publically available data sources, one cannot gain the same granularity as with a survey-based method. Nevertheless, the information found through examination of public data sources and data repositories indicates to what extent information about the market's state is being publicised.

Our analysis also focused on projects with information accessible in English. This precluded many projects that are assumed to be occurring in China. This inference can be made by looking at patent applications. China has accounted for nearly $60 \%$ of the total number of blockchain applications submitted by the USA, China, Japan, South Korea and Germany altogether through 2018, with its application total being nearly three times larger than the USA (Chen, 2020). Given this, the fact that only $8 \%$ of projects in our dataset were operating in China would indicate Chinese projects were most likely underrepresented. This is most likely the case as Chinese project information is not published in English and therefore, could not be included in this study.

There are also limitations of the project status labels that have been applied. In particular the labels of inactive and market-ready. A project that has been labeled as inactive may not necessarily indicate that it has failed or is discontinued. In some cases, this is most likely the case wherein our criteria a website no longer worked, for instance. However, even though we set a bar at one year of inactivity-this may not mean that a project has failed, but may also indicate that it is in hiatus. Similarly, the label of market-ready does not imply that a project is successful. Our criteria in judging this is that a project is deployed and being used in production internally or with clients, or that the project is being sold and is therefore market-ready.

One may argue that many projects may not accurately represent their true status with, for example, a large number of projects with an in-development status for many years. Indeed some projects have had this status for many years. It is interesting 
to speculate why they are still active on communications and on their websites. This may be explained as there are reasons to keep a project going on for marketing purposes if their use case will be useful in the future. Market-ready projects may also be overestimated as organizations can state they have productionlevel projects without any other stakeholders utilizing their solutions. For example, a startup that builds a blockchain solution can start to sell it and therefore be included in our classification as market-ready, even though there may not be any users and therefore not successfully representing a movement from in-development to production through successful trials and experiments.

Furthermore, looking at the dataset, out of all startups, only $29 \%$ of these projects are identifiable as market-ready, vs the entire dataset average of $23 \%$. Compared to public companies, for instance, here, $17 \%$ of projects are identifiable as market-ready. If one expected that many more startup projects would publicize solutions as market-ready, this is not strongly shown in the data. Therefore one could tentatively associate market-readiness as a measure of successfully creating a solution for the market and thereby supporting some inference that Hyperledger based technologies seem to have more success coming to the market than Ethereum ones, as seen in the earlier analysis.

This research is also a snapshot of the state of the blockchain market historically from today's perspective. This means that although some elements of the market's evolution have been presented, the full extent of all trends in the industry cannot be analyzed. For example, some projects in 2013 and 2014 are using the Ethereum blockchain. This is today's snapshot of their behavior as Ethereum was not launched until the middle of 2015. It was not possible to see what solutions they were using before Ethereum and, when and why they switched technologies.

Finally, it would be interesting to extend the dimensions of this research into other variables if enough information could be found on funding levels and even examine if the current pandemic situation has led to more opportunities for implementing DLT based solutions. Furthermore, this research has not examined in detail reasons for why projects have succeeded or failed beyond

\section{REFERENCES}

Androulaki, E., Manevich, Y., Muralidharan, S., Murthy, C., Nguyen, B., Sethi, M., et al. (2018). Hyperledger fabricc: a distributed operating system for permissioned blockchains. Proceedings of the thirteenth EuroSys conference on-EuroSys'18 Available at: https://dl.acm.org/citation.cfm?id=3190538 30, 1-15. doi:10.1145/3190508.3190538

Bajpai, C. P. (2017). How IBM and maersk will use the blockchain to change the shipping industry Available at: https://www.nasdaq.com/articles/how-ibm-andmaersk-will-use-blockchain-change-shipping-industry-2017-03-06 (Accessed September 2, 2020).

Boucher, P. (2017). How blockchain technology could change our lives, Brussels, Belgium: STOA. Available at: https://www.europarl.europa.eu/RegData/etudes/IDAN/2017/ 581948/EPRS_IDA(2017)581948_EN.pdf. doi:10.4324/9781315658315

Bünger, M. (2017). Blockchain for industrial enterprises: hype, reality, obstacles and outlook-IoT Agenda, Newton, MA, United States: Techtarget. Available at: https://internetofthingsagenda.techtarget.com/blog/IoT-Agenda/Blockchain-forindustrial-enterprises-Hype-reality-obstacles-and-outlook (Accessed September 24, 2020). looking at the statistics and making inferences. It would be interesting to explore several case studies with interviews. This may paint a better picture of the market's evolution of blockchain usage over time and enable discussion of best practises leading to more successful project outcomes for the deployment of blockchain in supply chains.

\section{CONCLUSION}

In this research, we have begun to map out how blockchain has evolved with respect to its usage in the supply chain sector. Utilizing a number of different parameters, we have investigated which sectors have seen projects take place, which blockchains are utilized, which organizations are leading and how successful projects have been. We have observed that the greatest concentration of projects is in the Agriculture/Grocery and Freight/Logistics sectors. We have confirmed market trends that blockchain projects have shifted from being startup (private company) led to public company led and that the most popular blockchain used has changed from Ethereum to Hyperledger. Finally, we see that there are more market-ready Hyperledger based projects and less inactive ones compared with Ethereum based projects and the entire dataset.

\section{DATA AVAILABILITY STATEMENT}

The raw data supporting the conclusions of this article will be made available by the authors, without undue reservation.

\section{AUTHOR CONTRIBUTIONS}

$\mathrm{NV}$ is the primary author and performed the analysis and wrote the paper. PT provided guidance on the research, edited the paper, provided citations, language editing and audience framing.

Casey, M. J., and Wong, P. (2017). Global supply chains are about to get better, Brighton, MA, United States: Harvard Business Review. Available at: https:// hbr.org/2017/03/global-supply-chains-are-about-to-get-better-thanks-toblockchain (Accessed September 24, 2020).

Chen, X. (2020). China dominates blockchain patent applications. London, United Kingdom: World IP Review. Available at: https://www. worldipreview.com/article/china-dominates-blockchain-patent-applicationsas-regulations-are-streamlined (Accessed September 24, 2020).

CoinMarketCap (2020). Bitcoin. Available at: https://coinmarketcap.com/ currencies/bitcoin/ (Accessed September 24, 2020).

Deloitte (2020). Deloitte's 2020 global blockchain survey from promise to reality, London, United Kingdom: Deloitte Insights. Available at: https://www2. deloitte.com/content/dam/insights/us/articles/6608_2020-global-blockchainsurvey/DI_CIR\%202020\%20global\%20blockchain\%20survey.pdf (Accessed September 24, 2020).

Etheruem (2020). Ethereum whitepaper. Available at: https://ethereum.org/en/ whitepaper/(Accessed September 24, 2020).

Falkheimer, J., and Heide, M. (2015). Trust and brand recovery campaigns in crisis: findus nordic and the horsemeat scandal. Int. J. Strat. Commun. 9 (2), 134-147. doi:10.1080/1553118x.2015.1008636 
Fosso Wamba, S., Queiroz, M. M., and Trinchera, L. (2020). Dynamics between blockchain adoption determinants and supply chain performance: an empirical investigation. Int. J. Prod. Econ. 229, 107791. doi:10.1016/j.ijpe.2020.107791

Google (2020). Google trends. Google trends Available at: https://trends.google. com/trends/explore?date=allandq=blockchain (Accessed September 24, 2020).

Groenfeldt, T. (2017). IBM and maersk apply blockchain to container shipping, Jersey, NJ, United States: Forbes. Available at: https://www.forbes.com/sites/ tomgroenfeldt/2017/03/05/ibm-and-maersk-apply-blockchain-to-containershipping/\#76b588293f05 (Accessed Sep 24, 2020).

Hughes, A., Park, A., Kietzmann, J., and Archer-Brown, C. (2019). Beyond Bitcoin: what blockchain and distributed ledger technologies mean for firms. Bus. Horiz. 62 (3), 273-281. doi:10.1016/j.bushor.2019.01.002

Hyperledger (2020). About-hyperledger. Hyperledger Available at: https://www. hyperledger.org/about (Accessed September 24, 2020).

Iansiti, M., and Lakhani, K. (2018). The truth about blockchain, Brighton, MA, United States: Harvard Business Review. Available at: https://hbr.org/2017/01/ the-truth-about-blockchain.

Kshetri, N. (2018). 1 Blockchain's roles in meeting key supply chain management objectives. Int. J. Inf. Manag. 39, 80-89. doi:10.1016/j. ijinfomgt.2017.12.005

Lin, J., and Lanng, C. (2020). Here's how global supply chains will change after COVID-19, Cologny, Switzerland: World Economic Forum. Available at: https://www.weforum.org/agenda/2020/05/this-is-what-global-supply-chainswill-look-like-after-covid-19/(Accessed September 24, 2020).

Liu, S. (2020). Amount raised for blockchain ICO projects 2017-2019, Tokyo, Japan: Statista. Available at: https://www.statista.com/statistics/804748/worldwideamount-crytocurrency-ico-projects/(Accessed September 24, 2020).

Min, H. (2019). Blockchain technology for enhancing supply chain resilience. Bus. Horiz. 62 (1), 35-45. doi:10.1016/j.bushor.2018.08.012

Morkunas, V. J., Paschen, J., and Boon, E. (2019). How blockchain technologies impact your business model. Bus. Horiz. 62 (3), 295-306. doi:10.1016/j.bushor. 2019.01.009
Nakamoto, S. (2008). Bitcoin: a peer-to-peer electronic cash system Available at: https://bitcoin.org/bitcoin.pdf.

O'Marah, K. (2017). Blockchain for supply chain: enormous potential down the road, Jersey, NJ, United States: Forbes. Available at: https://www.forbes.com/ sites/kevinomarah/2017/03/09/blockchain-for-supply-chain-enormouspotential-down-the-road/\#775af6f73db5 (Accessed September 24, 2020).

Petersen, M., Hackius, N., and Von See, B. (2018). Mapping the sea of opportunities: blockchain in supply chain and logistics, It-Information Technology 60(5-6), 263-271. doi:10.1515/itit-2017-0031

Pilkington, M. (2016). "Blockchain technology: principles and applications," in Research handbook on digital transformations. Editors F. X. Olleros and M. Zhegu (Cheltenham, United Kingdom: Edward Elgar Publishing), 1-39.

Tasca, P., Vigliotti, M. G., and Gong, H. (2018). Risks and challenges of initial coin offerings. J. Dig. Bank. 3 (1), 81-96.

UCL Centre for Blockchain Technologies (2019). Distributed ledger technology in the supply chain Available at: http://blockchain.cs.ucl.ac.uk/wp-content/ uploads/2019/08/DLT-in-the-Supply-Chain_UCL-CBT.pdf (Accessed January $18,2021)$.

Xiu, C., and Klein, K. K. (2010). Melamine in milk products in China: examining the factors that led to deliberate use of the contaminant. Food Pol. 35, 463-470. doi:10.1016/j.foodpol.2010.05.001

Conflict of Interest: The authors declare that the research was conducted in the absence of any commercial or financial relationships that could be construed as a potential conflict of interest.

Copyright (C) 2021 Vadgama and Tasca. This is an open-access article distributed under the terms of the Creative Commons Attribution License (CC BY). The use, distribution or reproduction in other forums is permitted, provided the original author(s) and the copyright owner(s) are credited and that the original publication in this journal is cited, in accordance with accepted academic practice. No use, distribution or reproduction is permitted which does not comply with these terms. 


\section{APPENDIX}

APPENDIX 1 | Explanation of the main fields of data collection.

\section{Field name}

Project name

Website

Type of organization behind the project

Sector of operation

Project location

Region

Year of founding

Project status

Supply chain application area

Organizations involved in the project

Name of DLT utilized

\section{Explanation of field}

The name of the project or company if only a single company were leading this project

The website of the project

The organization type that is leading the project, whether this was: Startup (or private company), government initiative, public company, consortium

Assessment of most suitable sector for the project

What country(s) the project is primarily operating in

What region(s) the project is primarily operating in

The year the project was founded

The status of the project: Inactive, in-development, market-ready

The area within the supply chain where this project is applying blockchain: Product tracing/tracking, logistics, financial transactions, retail operations, circular economy

Other organizations involved in the project if any

The DLT that was primarily utilized

\section{APPENDIX 2 | Example of project-specific fields.}

\section{Field}

Project name

Website

Type of organization behind the project

Sector of operation

Project location

Region

Year of founding

Project status

Supply chain application area

Organizations involved in the project

Name of DLT utilized

\section{Information}

Ambrosus

https://ambrosus.com/

Startup

Pharma/healthcare

Switzerland

EMEA

2017

In-development

Product tracing/tracking; logistics

Nongshim, UN 10YFP, european institute of innovation and technology AMB-NET (ethereum) 